Ariana Yamara Vivar Astudillo; Juan Carlos Erazo Álvarez; Cecilia Ivonne Narváez Zurita

http://dx.doi.org/10.35381/r.k.v6i10.686

\title{
La cadena de valor como herramienta generadora de ventajas competitivas para la Industria Acuícola
}

The value chain as a tool for generating competitive advantages in the Aquaculture Industry

\author{
Ariana Yamara Vivar-Astudillo \\ ariana.vivar@psg.ucacue.edu.ec \\ Universidad Católica de Cuenca, Cuenca \\ Ecuador \\ https://orcid.org/0000-0001-5204-7546 \\ Juan Carlos Erazo-Álvarez \\ jcerazo@ucacue.edu.ec \\ Universidad Católica de Cuenca, Cuenca \\ Ecuador \\ https://orcid.org/0000-0001-6480-2270 \\ Cecilia Ivonne Narváez-Zurita \\ inarvaez@ucacue.edu.ec \\ Universidad Católica de Cuenca, Cuenca \\ Ecuador \\ https://orcid.org/0000-0002-7437-9880
}

Recibido: 05 de marzo de 2020

Revisado: 12 de marzo de 2020

Aprobado: 03 de mayo de 2020

Publicado: 19 de mayo de 2020

\section{RESUMEN}

El objetivo de la investigación fue proponer sistemas de mejoras en cada uno de los eslabones de las actividades que realiza Industria Acuícola Vikas Cía. Ltda. Para la obtención de los datos se realizó una investigación bajo un diseño no experimental, el estudio tuvo un enfoque mixto y un alcance descriptivo. Se identificaron problemas en las diferentes áreas de la empresa como falta de capacitaciones, carencia de formatos para registro productivos, planes de bonificaciones salariales, registro para logística interna y externa; sin embargo, la empresa mantiene una eficiente estructura organizacional. Sobre la base de este estudio se propuso la implementación de diferentes actividades en la cadena de valor para generar ventaja competitiva que permita aumentar valor al producto y optimizar los procesos productivos, a lo largo de la cadena de valor. 
Descriptores: Acuicultura marina; tasa de crecimiento; crecimiento económico; productividad. (Palabras tomadas del Tesauro UNESCO).

\begin{abstract}
ABTRACT
The objective of the research is to propose improvement systems in each link of the activities carried out by Vikas Aquaculture Industry, Cia. Ltd. Data was collected trhough an investigation under a non-experimental design, and the study had a mixed-methods approach with a descriptive scope. Problems were identified in the different areas of the company such as lack of training, lack of formats for production registration, salary bonus plans, registration for internal and external logistics; however, the company maintains an efficient organizational structure. Based on this study, the implementation of different activities in the value chain was proposed to generate a competitive advantage that would increase the value of the product and optimize production processes throughout the value chain.
\end{abstract}

Descriptors: Marine aquaculture; growth rate; economic growth; productivity. (Words taken from the UNESCO Thesaurus).

\title{
INTRODUCCIÓN
}

El Ecuador es considerado como el segundo país más grande en producción de camarón a nivel mundial, ubicándose como el primer producto de exportación alcanzando aproximadamente 165.000 toneladas métricas de producto al año, debido a sus innovadoras tecnologías de sistemas intensivos que permiten sembrar más larvas de camarón por piscinas segúncifras del (Banco Central del Ecuador, 2020).Por lo tanto, este sector productivo del país tiene un gran peso en la balanza comercial de productos no petroleros y un fuerte impacto en el ámbito económico y social; el aumento de la producción de camarón ayudará a contribuir al PIB del país por lo que es importante optimizar la matriz productiva y buscar ayudas estatales que beneficien a esta industria tan importante del Ecuador.

Por esta razón, (Piedrahita, 2018) indica que es fundamental el apoyo del gobierno ecuatoriano para elaborar un plan de mejoramiento competitivo con la participación de las entidades más importantes del sector privado y público. Esto se debe a los costos que genera toda la cadena productiva y la cantidad de empleos ligada a esta actividad 


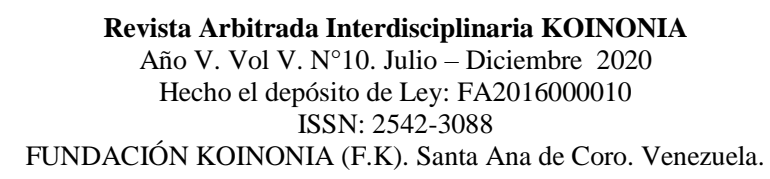

Ariana Yamara Vivar Astudillo; Juan Carlos Erazo Álvarez; Cecilia Ivonne Narváez Zurita

económica, en efecto las empresas dedicadas a rubro en la actualidad deben sobrevivir, sercompetitivos a nivel internacional, esto obliga a que la gran mayoría de empresas logren la mayor producción con los recursos que tienen a su disposición o que generen una posición relativamente favorable en el mercado con relación a sus rivales, lo cual les permitirá permanecer y expandirse.

En consecuencia es muy importante que las empresas mantengan una ventaja competitiva obtenida mediante la correcta ejecución de la cadena de valor, la cual determina varios factores como el costo, la calidad, la respuesta a tiempo, y flexibilidad, esto conlleva a la rentabilidad de la organización a pesar de las debilidades que se presentan a nivel macro, siendo estas: la vulnerabilidad de los mercados internacionales, un inadecuado marco legal con muchos formalismos innecesarios, la falta de apoyo para combatir la delincuencia y el poco apoyo a financiamientos para la producción y exportación sumando a esto la insuficiencia eléctrica.

Dentro de la provincia de El Oro existen varias empresas dedicas a la explotación y comercialización de camarón, siendo una de estas, Industria Acuícola VikasCia. Ltda. que se encuentra ubicada en el cantón Arenillas, esta organización cuenta con 10 colaboradores de campo y 5 administrativos, además genera empleo a aproximadamente 30 personasadicionales cada 2 mesesdurante el tiempo que dure la cosecha, esto se debe a su sistema de producción intensivo del cual se obtiene un promedio de $16.000 \mathrm{lb}$ por cada piscina de media hectárea, esta técnica consiste en 3 etapas, las cuales son: siembra en raceways, precrias y finalmente engordes hasta obtener el producto final.

La empresa mantiene estructurado un sistema para producir camarón que permite ser eficiente en sus costos, sin embargo, el problema radica en la inestabilidad de precios a nivel internacional y la disminución de liquidez en las empresas para cubrir los costos de producción, debido a que no se mantiene una estructura correcta en toda la cadena de valor. En la actualidad los negocios son cada vez más competitivos en el mercado extranjero y esto obliga a que se optimicen los recursos que disponen y que generen ventajas competitivas en comparación a sus competidores. 
Por otra parte, la ventaja competitiva se construye proporcionando valor para los compradores y se manifiesta cuando los costos se reducen y el rendimiento aumenta (Presutti y Mawhinney, 2014). De esta manera se presenta la relaciónen la cual Porter (2015) afirma: "La estructura de la industria moldea la cadena de valor y refleja las competencias" (p.144). Ahora bien, el objetivo principal es identificar los pasos esenciales para el análisis correcto de cada uno de los eslabones y establecer los procedimientos para las actividades que influyen en el proceso de producción, con el fin de obtener una optimización de costos y competir en el mercado internacional. En este sentido, la generación de costos en cada etapa de producción ha constituido para Industria Acuícola Vikas Cía. Ltda. una herramienta valiosa que permite identificar las actividades más relevantes desde una visión estratégica, apoyada en la diferenciación y en sus precios.

\section{Referencial teórico}

\section{La cadena de Valor, como ventaja competitiva}

En este sentido, (Porter, 1985), estableció un modelo que es un sistema que genera valor a una empresa, a la cual la llamo cadena de valor, las actividades de los proveedores, miembros del canal de distribución, y clientes. Su concepto subraya la importancia de los vínculos, horizontalmente entre los aspectos internos de una empresa y actividades;verticalmente entre proveedores, miembros del canal, y clientes. Tal como se observa en la Figura 1. 
Infraestructura de la empresa

Gestión de Recursos Humanos

Figura 1. Modelo de la cadena de valor. Fuente: Porter (1985)

La cadena de valor aborda dinamismos beneficiando directamente a la producción (actividades primarias) o influir indirectamente en esto (actividades de apoyo); dependiendo de este análisis, la empresa puede buscar formas de diferenciarse en las áreas de precio, calidad, servicios, otorgamiento de descuentos en ventas, distribución de comisiones por ventas, entre otros.

Por consiguiente, las actividades primarias agregan valor directamente al proceso de producción, no son necesariamente más importantes que las actividades de apoyo. Hoy en día, la ventaja competitiva se deriva principalmente de mejoras tecnológicas o innovaciones en modelos o procesos de negocios. Por lo tanto, las actividades de apoyo como "sistemas de información" o "administración general" suelen ser la fuente más importante de ventaja de diferenciación, por otro lado, las actividades primarias suelen ser la fuente de la ventaja de costos, donde estos pueden identificarse fácilmente para cada actividad y administrarse adecuadamente (Jurevicius, 2013).

El modelo planteado por (Porter, 1985) menciona que la cadena de valor se centra en la meta y visión diseñada por las empresas, como un procedimiento en el cual se encuentra sobre varios procesos pequeños de diferentes áreas que forman un sistema global, en el 


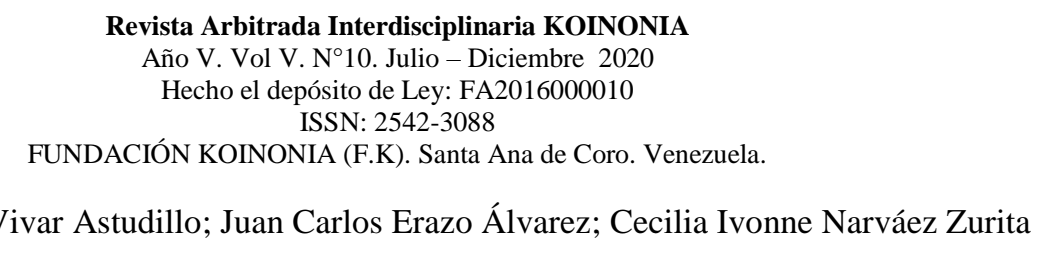

cual intervienen los recursos de la organización, los costos se determinan en función de todas las actividades realizadas a lo largo de la cadena de valor lo que consecuentemente liga a la ganancia de la organización.

Dada la importancia de la cadena de valor, se divide el análisis de la cadena de valor en cinco actividades principales. Luego, los divide en cuatro actividades que ayudan a apoyar las actividades primarias. Los eslabones de la cadena de valor se dividen en actividades primarias y secundarias. De las cuales las más importantes son: logística interna y externa, las operaciones de la empresa, marketing, y servicio. La idea de los cinco conjuntos de actividades es crear un valor que exceda el costo de llevar a cabo esa actividad, generando así una mayor ganancia. Según (Porter, 1985) las actividades principales son:

- Logística de entrada: Involucra relaciones con proveedores e incluye todas las actividades necesarias para recibir, almacenar y distribuir insumos.

- Operaciones: Son todas las actividades necesarias para transformar las entradas en salidas.

- Logística de salida: Incluye todas las actividades necesarias para recopilar, almacenar y distribuir la salida.

- Marketing y ventas: Las actividades informan a los compradores sobre productos y servicios, los inducen a comprarlos y facilitan su compra.

- Servicio: Incluye todas las actividades necesarias para mantener el producto funcionando eficazmente para que se venda y entregue.

De la misma manera, (Porter, 1985) indica que las actividades secundarias son:

- Adquisiciones: Es la adquisición de insumos o recursos para la empresa.

- Gestión de recursos humanos: Consiste en todas las actividades involucradas en el reclutamiento, contratación, capacitación, desarrollo, compensación.

- Desarrollo tecnológico: Se refiere al equipo, hardware, software, procedimientos y conocimientos técnicos que influyen en la transformación de la empresa de entradas en salidas. 


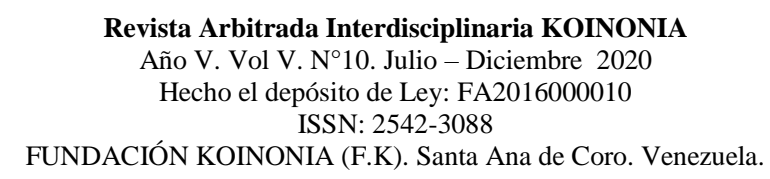

Ariana Yamara Vivar Astudillo; Juan Carlos Erazo Álvarez; Cecilia Ivonne Narváez Zurita

- Infraestructura: Atiende las necesidades de la compañía y une sus diversas partes, consta de funciones o departamentos como contabilidad, legal, finanzas, planificación, asuntos públicos, relaciones gubernamentales, garantía de calidad y gestión general.

Para lograr una gestión eficaz en la cadena de valor se requiere dejar a un lado la forma burocrática tradicional de las organizaciones, con sus límites, mentalidad que conduce a varias disfunciones que pueden ser destructivas para la empresa. La integración es fundamental para un estado sin fronteras donde los elementos comunes prevalecen y las disfunciones se minimizan, otra manera es centrándose en el cliente como el propósito común de todos en la organización, reduciendo significativamente el reto de llegar a la integración en toda la organización (Presutti y Mawhinney, 2013).

Por lo anteriormente expuesto, generar valor en una empresa mediante la correcta gestión es muy importante, ya que permite competir en el mercado y a su vez generar dividendos para sus accionistas. Por esta razón las empresas deben llegar a la satisfacción de los clientes, ventaja ante los competidores y la rentabilidad esperada, por lo que debe ser una preocupación constante de los gerentes debido a que se deben crear estrategias para lograr la optimización de costos y liquidez.

De esta manera, (Crain\& Abraham, 2008) proponen un método de cinco pasos para descubrir las necesidades estratégicas particulares de un cliente basado en una aplicación única para estudiar la cadena de valor, en la cual incluyen: identificar nuevas oportunidades comerciales de alto valor y fortalecer la relación de cliente de empresa a empresa, además de aclarar sus prioridades estratégicas permite una mejor alineación de acciones con los resultados deseados (Amadeo, 2019). Las actividades en las cadenas de valor se pueden ajustar con precisión para obtener una ventaja competitiva, mediante implementación de la planificación estratégica que es el proceso organizacional para tomar estas decisiones importantes.

Porter (1998) menciona que cada proceso dentro la organización tiene que tener una ventaja competitiva a largo plazo, siendo esta en forma de diferenciación o en costos, por 


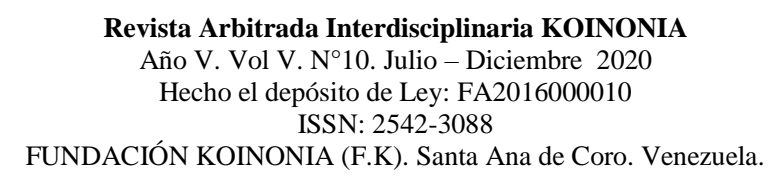

Ariana Yamara Vivar Astudillo; Juan Carlos Erazo Álvarez; Cecilia Ivonne Narváez Zurita

lo que es muy importante analizar cada eslabón de una forma individual para que los gerentes o administradores puedan estudiar por separado, con el objetivo de tomar las decisiones acertadas. Por lo cual, es importante tener un equipo de gestión eficaz, que pueda aportar valor mediante una metodología de flujo o un enfoque de gestión enfocado en cumplir las metas trazadas por la empresa.

El sistema de flujo de valor trasciende la forma tradicional de mentalizar las etapas del proceso empresarial, esto resalta la importancia de que el gerente participe en todos los aspectos del proceso: desde el proveedor hasta el cliente y, si es posible, hasta el cliente del cliente, con este enfoque se ignoran los límites funcionales y en muchas organizaciones ahora se acepta que el gerente controle el proceso total, desde la compra de bienes de entrada y servicios hasta la etapa final de satisfacción del consumidor si posible (Heene \& Sanchez, 2010).

De esta manera, la cadena de valor se enfoca en el concepto de que una empresa dedicada a la industria formada por cada una de sus actividades, estén determinadas por los costos y su utilidad, por cuanto el éxito se enfoca en el flujo de valor o del método de la cadena total respaldado por la interacción entre tres grupos claves, lo cuales son: los clientes, proveedores externos y los departamentos involucrados en las actividades primarias y secundarias de la organización (Basu, 2017). Con buena dedicación y atención, los gerentes serán capaces de generar valor para su negocio, resultando en beneficios en última instancia para todas las jerarquías, clientes y aliados, mediante la cadena de valor que genera competencia ante la industria(Picón, Erazo y Narváez, 2019). Por su parte, (Simatupang, Piboonrungroj \& Williams, 2016) presentan un modelo conceptual que consta de cuatro pasos: descubrimiento de valor, diseño de valor, entrega de valor y captura de valor, debido a que los autores sustentan que la cadena de valor de Porter asume que una organización es un sistema compuesto de entradas, transformación procesos y productos; cada actividad en el sistema implica la adquisición y consumo de recursos, sin embargo destacan que poca atención se ha dado al desarrollo del pensamiento de la cadena de valor, que implica una cadena de actividades vinculadas entre sí para mantener el valor del proceso de producción. 


\section{La ventaja competitiva en la industria}

El modelo de (Porter, 1985), postula que la ventaja competitiva es impulsada por la organización de la industria y exposiciones e influenciado por esa estructura, desde esa perspectiva, el entorno determina en gran medida la ventaja competitiva y el rendimiento, ya que todas las actividades deben tener control en los costos que influyen en la creación de una ventaja. Por otro lado, (Presutti\& Mawhinney, 2013),como se observa en la Figura 2 indican que una organización logra distinguirse de otra cuando genera valor a cada uno de los requerimientos del cliente o proveedor, sin centrase solo en el producto si no también tomando en cuenta actividades como atención al cliente o el nivel de logística que tenga la empresa.

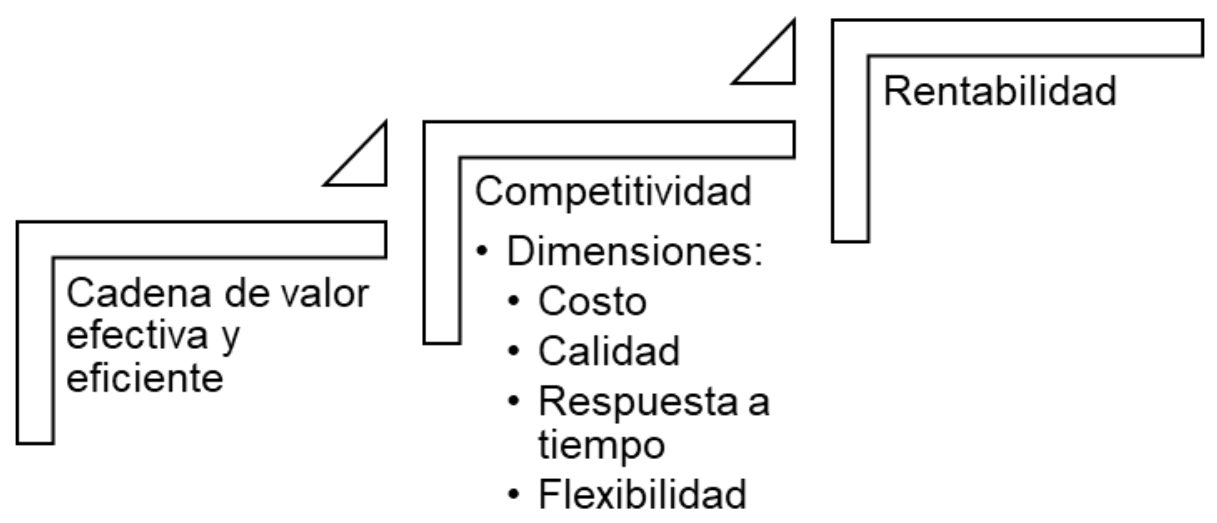

Figura 2. Gestión de la cadena de valor y éxito competitivo. Fuente: Presutti y Mawhinney (2013)

Prosiguiendo con lo planteado, (Presutti \& Mawhinney, 2013), afirman que la ventaja competitiva se construye proporcionando valor para los clientes y se manifiesta cuando los costos se reducen y el rendimiento aumenta, la correcta implementación de la cadena de valor, conlleva a la competitividad del mercado, la ventaja competitiva obtenida mediante la correcta ejecución de los procesos determina varios factores como el costo, la calidad, la respuesta a tiempo y flexibilidad, la cual conlleva a la rentabilidad de la organización. 
Ariana Yamara Vivar Astudillo; Juan Carlos Erazo Álvarez; Cecilia Ivonne Narváez Zurita

Así mismo, (Porter, 2015) plantea que el desempeño óptimo de una empresa procede de los precios más altos sustentables y de los costos más bajos que se puedan mantener a largo plazo, ya que son factores generadores de ventajas competitivas. Por su parte, una ventaja competitiva es lo que hace que los bienes o servicios de una entidad sean superiores a todas las demás opciones del cliente, el término se utiliza comúnmente para las empresas y las estrategias funcionan para cualquier organización, país o persona en un entorno competitivo (Amadeo, 2019). Hay dos enfoques diferentes sobre cómo realizar el análisis, que dependen de qué tipo de ventaja competitiva desea crear una empresa las cuales son: ventaja de costo o diferenciación(Jurevicius, 2013).

Es por eso, que (Heene \& Sánchez, 2010), mencionan queel alcance competitivo es un medio poderoso que permite crear una oportunidad, una estrategia coordinada que compita a nivel nacional o global puede lograr una ventaja competitiva sobre los rivales, las organizaciones pueden aprovechar las ventajas potenciales en realizar actividades en lugar de utilizar proveedores externos.

La competencia no se trata principalmente de capturar la cuota de mercado, cliente y los perfiles de los competidores están cambiando constantemente; y la competencia se produce simultáneamente en la unidad de negocio y niveles corporativos, por tal motivo, los líderes tienden a enfocarse en expandir la demanda total al atraer nuevos usuarios, desarrollando nuevos usos para sus productos o servicios, defender la cuota de mercado es importante para ellos (Kluyver \& Pearce, 2015).

Para la formulación de la estrategia se debe hacer un análisis de las principales fortalezas de los competidores clave: las debilidades y su comportamiento pasado; evaluando los éxitos y fracasos de los competidores ayudan a predecir su futuro comportamiento. Finalmente, estudiar la estructura organizativa de un competidor y la cultura puede ser perspicaz; un competidor altamente estructurado y orientado a los costos es poco probable que se plantee un desafío exitoso con una innovación (Presutti \& Mawhinney, 2013). Al analizar patrones competitivos, a menudo es útil asignar roles a competidores particulares, en muchos mercados es posible identificar un líder, uno o más retadores, y un número de seguidores. 


\section{Revista Arbitrada Interdisciplinaria KOINONIA \\ Año V. Vol V. $\mathrm{N}^{\circ} 10$. Julio - Diciembre 2020 \\ Hecho el depósito de Ley: FA2016000010 \\ ISSN: 2542-3088 \\ FUNDACIÓN KOINONIA (F.K). Santa Ana de Coro. Venezuela. \\ Ariana Yamara Vivar Astudillo; Juan Carlos Erazo Álvarez; Cecilia Ivonne Narváez Zurita}

Así mismo, los avances tecnológicos han permitido a las empresas diseñar y construir más rápidamente, vender a través de múltiples canales, reaccionar instantáneamente a las demandas cambiantes y reducir los costos simplemente al subcontratar una actividad. Para lograr una ventaja competitiva, una organización en última instancia ofrece más valor a un costo igual o menor.

Por su parte, (Grant, 2010), menciona que al analizar una cadena de valor en términos de ventaja competitiva, la idea es comparar los aspectos de la cadena de valor de los competidores y las actividades de creación de valor de la empresa,por cuantocontribuyen a una ventaja en la competencia del mercado, esta es una forma de estrategia utilizada para analizar los procesos internos en las organizaciones, con el fin de visualizar los procesos más importantes y estar en constantes mejoras que puedan darse para cumplir con los objetivos planteados.

Por otro lado, (Ahokangas, Juho \& Haapanen, 2010), sugieren el aumento del dinamismo del mercado y la continua evolución de los recursos, por cuanto contribuyen al desarrollo de ventajas competitivas temporales utilizadas en la internacionalización de las empresas, además indican que las ventajas competitivas sostenibles para la internacionalización surgen de las ventajas temporales a través de un ciclo de vida a medida que disminuyen los efectos del dinamismo del mercado y la evolución de los recursos.

En este sentido, (Artieda, 2015) plantea la aplicación de herramientas estratégicas como el sistema de costos con un enfoque gerencial para que así las empresas generen valor en el proceso de gestión, cada vez las empresas se enfrentan al mundo moderno, con evoluciones en sistemas de competencias, tecnología, normas de calidad, e integraciones vertical y horizontales de procesos, por esta situación las empresas necesitan tener eficiencia y eficacia ya que son generadores de empleo, y dan un valor agregado a todo el ciclo de producción como herramienta estratégica para toma de decisiones gerenciales.

En función de lo planteado, (Musa,Firas \& Mahmoud, 2014), proponen identificar el alcance de la correcta implementación de la cadena de valor en las organizaciones para 
que puedan lograr y mantener una ventaja competitiva, el estudio recomienda que las empresas capaciten a sus empleados, sobre estrategias empresariales, como ejercer el análisis de la cadena de valor, calcular el costo unitario de producción para lograr y mantener una optimización de costos y estrategias de diferenciación, por cuanto los autores sustentan que la ventaja competitiva se basa en la reducción de costos y se puede lograr mediante la optimización de los sistemas de producción.

Habiendo elegido una posición competitiva, el primer desafío para una organización es entregar esto de la manera más eficiente posible que representa la capacidad de alcanzar el tope actual de productividad a lo largo del proceso, representando la elección estratégica, la eficiencia con la que se despliegan los recursos existentes de activos y capacidades, es decir, la práctica de mejora continua, en este sentido, probablemente haya pocos requisitos para agregar nuevos recursos, combinando nuevas actividades 0 mucho cambio requerido a la forma actual de operar o modelo de negocio lo que será un cambio radical a las empresas con el fin de mejorar la efeciencia de costos y productividad (Collis y Anand, 2019).

A traves de la ventaja competitiva existen factores internos y externos los cuales son capaces de generar competitividad en los mercados, los aspectos externos por lo general son los volátiles debido a que existen siempre cambios de acuerdo a las necesidades y el entorno por lo que debe estar siempre lista la empresa para responder a tiempo, lo que implica mantener una mayor capacidad para aprovechar las oportunidades del mercado, esta capacidad se logra siempre y cuando cuente con el conomiento, sepa identificar los recursos y tenga flexibilidad de respuesta(Ortega, Erazo y Narváez, 2019). En la figura 3 se evidencia que existen 4 aspectos internos que permiten alcanzar la meta y ser competitivos en el mercado: 


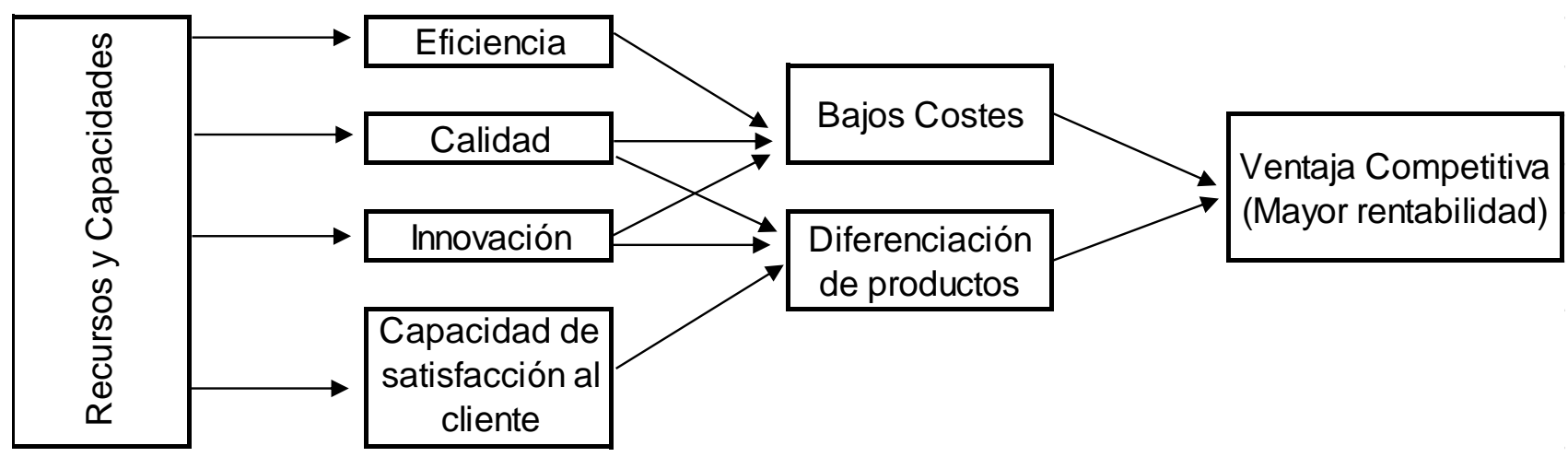

Figura 3. Factores internos de creación de ventaja competitiva. Fuente: Maroto (2017)

Prosiguiendo con lo expuesto, (Maroto, 2017), expresa que los factores internos son los mas importantes para generar y mantenerla competitividad dentro en una organización, siendo los recursos y las capacidades el origen para llevar a la eficiencia, además de mejorar la calidad que se refiere a la diferenciación y costo que da igual a una mayor productividad, a la innovacion que son los procesos en los que intervienen los costos, o producto que lo logra la diferenciación, o por ultimo la satisfacción del cliente en cual se liga a al diferenciación.

Por último, (Kaleka \& Morgan, 2017), afirman que en los últimos años, el concepto de ventaja competitiva ha tomado protagonismo en las discusiones de estrategia comercial; por eso, uno de los principales los desafíos que enfrentan las organizaciones hoy en día es cómo tener una ventaja competitiva, las compañías no podrían sobrevivir, a menos que se esfuercen para crear dos estrategias corporativas, de las cuales son: estrategia de costos que consiste en procesar la cadena de valor en la mayoría de manera eficiente, sin comprometer la calidad del producto y además tener la capacidad de ser creativo e innovador.

\section{MÉTODO}

El estudio tuvo un enfoque mixto, bajo un diseño no experimental, el cual es un proceso que recoge, estudia, enlaza datos cuantitativos y cualitativos, para de esta manera cumplir los objetivos planteados, (Hernández, Fernández \&Baptista, 2014) lo cual 
permitió tener una perspectiva amplia y profunda que ayudó a tener datos más variados, lo que facilitó a la formulación del planteamiento del problema con mayor claridad, teniendo un alcance descriptivo (Erazo \& Narváez, 2020). La técnica que se utilizó fue la encuesta con el objetivo de levantar toda la información que se pueda abarcar y de esta manera analizar las variables. El cuestionario fue el instrumento elegido para la presente investigación (Baena, 2017).

\section{Universo de estudio y tratamiento muestral}

El universo que interviene en la investigación es reducido, por lo que se toma como población o universo de estudio a todas las personas que forman parte de la empresa Industria Acuícola Vikas Cía. Ltda. lo cual se compone de 15 personas y se distribuyen por áreas los cuales son:

- Área Administrativa: 2 personas

- Área Financiera: 1 persona

- Área de Proveeduría y Bodega: 1 persona

- Área de Producción: 11 personas

\section{Tratamiento estadístico de la información}

Se obtuvieron datos a mediante cuestionarios y a través de los formularios realizados por Google (https://docs.google.com/forms), estos fueron procesados en tablas de datos que recopilan las respuestas de las personas involucradas en la investigación y se tabularon los resultados en el programa Excel versión 2016.

\section{RESULTADOS}

Se presentan los resultados realizados mediante la utilización de instrumentos de investigación a las áreas de la empresa Industria Acuícola Vikas. Cía. Ltda, los mismos que se presentan a continuación: 


\section{Revista Arbitrada Interdisciplinaria KOINONIA \\ Año V. Vol V. $\mathrm{N}^{\circ} 10$. Julio - Diciembre 2020 \\ Hecho el depósito de Ley: FA2016000010 \\ ISSN: 2542-3088 \\ FUNDACIÓN KOINONIA (F.K). Santa Ana de Coro. Venezuela. \\ Ariana Yamara Vivar Astudillo; Juan Carlos Erazo Álvarez; Cecilia Ivonne Narváez Zurita}

Área administativa:

Esta área esta inmersa en las decisionas más importante que toma la compañía por lo cual en un porcentaje del $50 \%$ afirman que los objetivos que mantiene la empresa son cuantificables y medibles, mientras el otro $50 \%$ indica que no es así, en referencia a que si existe una asignación de recursos en base a los obetivos definidos coinciden en un $100 \%$.

Es importante mencionar que la empresa mantiene un alto grado de cumplimiento de las necesidades de sus proveedoresm clientes, empleados y directivos, lo que conlleva a un alto nivel de fidelidad de los clientes, debido que conoce la correcta estructura del mercado en el se comercializa el camarón, y tambien mantiene muy claro cuales son los comepetidores y el tipo de empresa que es cada uno de ellos.

El área administrativa afirma con un $100 \%$ de que todos los puestos de trabajo tienen una descripcion de cada una de sus funciones, sin embargo es importante mencionar que aunque tiene una buena estructura organizacional no la empresa cuenta con una programa de escala salarial establecida en funcion a los desempeños laborales y tampoco mantienen un sistema de capacitaciones al personal, ni un correcto procedimiento para la evaluación de sus desempeño.

Con un pocertanje del $100 \%$ los encuestados aseveran que las instalaciones de empresa en la que laboran son modernas e invierte constantemente en innovación tecnológica para mejorar sus procesos de producción. Además mantiene un correcto protocolo al momento de las compras de materias primas y estan de acuerdos en los procesos productivos que tiene la empresa desde la siembra de la larvas y cosecha de camarón.

\section{Área Financiera:}

Los resultados indican que la empresa cuenta con un sistema de analisis y seguimiento de del riesgo de los clientes que componen la parte mas importante de la facturación, de igual manera se analiza la rentabilidad de los recursos propios de manera ocasional, sin embargo no dispone de un sistema de analisis de sus costos financieros derivados de las condiciones de pago ofrecidas por los proveedores y los responsables de los invetarios 
no son informados periódica y sistemáticamente del costo financiero del mantenimiento de los mismos aunque tiene un software que les permite ingresa sus movimientos contables y cuenta con un correcto descargo de inventarios para obtener el costo de venta final.

La organización no brinda frecuentemente capacitaciones sobre actualizaciones contables, financieras y tributarias. Un beneficio importante es que por estan inmesar en la actividad agropecuaria del pais mantiene preferencias tributarias lo cual le permite tener mas liquidez en su flujo.

\section{Área de producción:}

El área productiva es una de las mas importante de la empresa ya que de esta área se produce el producto final, los datos arrojados indican que en el ultimo año con un $72 \%$ sí se han desarrollado nuevos procedimientos para producir en alguna etapas productivas y un $27.3 \%$ afirman que no es así. Además el $90.90 \%$ de los colaboradores de esta área señalan que las tareas diarias son informadas por forma escrita y el $9.1 \%$ que eson informados de forma verbal. Las especificaciones de las labores diarias son muy imprtantes para que el trabajo fluya de una manera adecuada el $72.7 \%$ afirman que las especificaciones respecto a sus actividades para desarrollar en el puesto de trabajo son claras y se mantienen procesos docuementados, además que la información fluye libremente entre las distintas áreas de la empresa para facilitar el trabajo encomendado, mientras un $27.3 \%$ indican que no es así.

El $63.6 \%$ del personal asegura que no existe un manual de funciones y el $36.4 \%$ indican si existe. El $81.8 \%$ de los trabajadores aseveran que existe una responsable para cada proceso que se ejecuta en la empresa, que existe un sistema que permite medir la eficiencia de cada proceso y que tienen el apoyo suficiente por parte del jefe de campo, mientras el $18.2 \%$ afirma lo contrario y finalmnete con el $90.9 \%$ indica que el área de proveduría abastece de forma correcta el balanceado e insumos para la producción y el $9.1 \%$ afirman que no. 
Área de proveeduría:

Está área es una de las que más ayudaría a la optimización de costos por lo que plantearon alguna preguntas al encargo de proveeduría siendo los resultados lo siguientes:

La empresa sí:

- Conoce la empresa las condiciones de compra que su proveedor habitual ofrece a otras empresas de la competencia

- Utiliza la empresa distintos criterios (precio, calidad, servicio) de selección para gestionar la compra

- Ayuda la empresa a sus proveedores suministrándoles previsiones de compras, trimestrales y mensuales de acuerdo a la producción

- La empresa maneja stock de mínimos y máximos para realizar las compras de insumos o balanceado

- La empresa maneja tiempo de pedidos, es decir días de plazos de entrega desde que realiza el pedido hasta que llegan los productos para evitar desabastecimientos

- La empresa maneja kardex en bodegas

- Disponen de un procedimiento para recibir los productos y asegurar la calidad de los mismos

La empresa no:

- Ha evaluado la empresa la posibilidad de comprar a proveedores alternativos a los actuales

- Ha estudiado la empresa la posibilidad de fabricar o realizar por si mismo insumos o balanceado

- Ha estudiado la empresa la posibilidad de fabricar o realizar por si mismo insumos o balanceado 


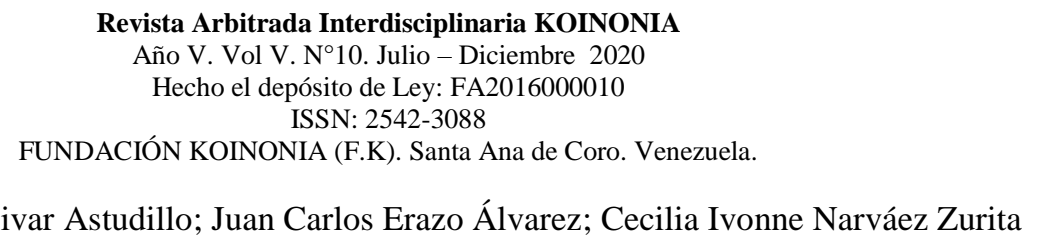

\section{PROPUESTA}

Una cadena de valor es un conjunto de actividades que una organización lleva a cabo para crear valor para sus clientes, la forma en que se realizan las actividades de la cadena de valor determina los costos y afecta las ganancias, por lo que esta herramienta puede ayudar a comprender las fuentes de valor para la organización, además describe las actividades dentro y alrededor de la empresa, y las relaciona con un análisis de la fuerza competitiva, por lo tanto, se evalúa qué valor agrega cada actividad particular. A continuación en la Figura 4 se establece el esquema de la propuesta de la presente investigación:

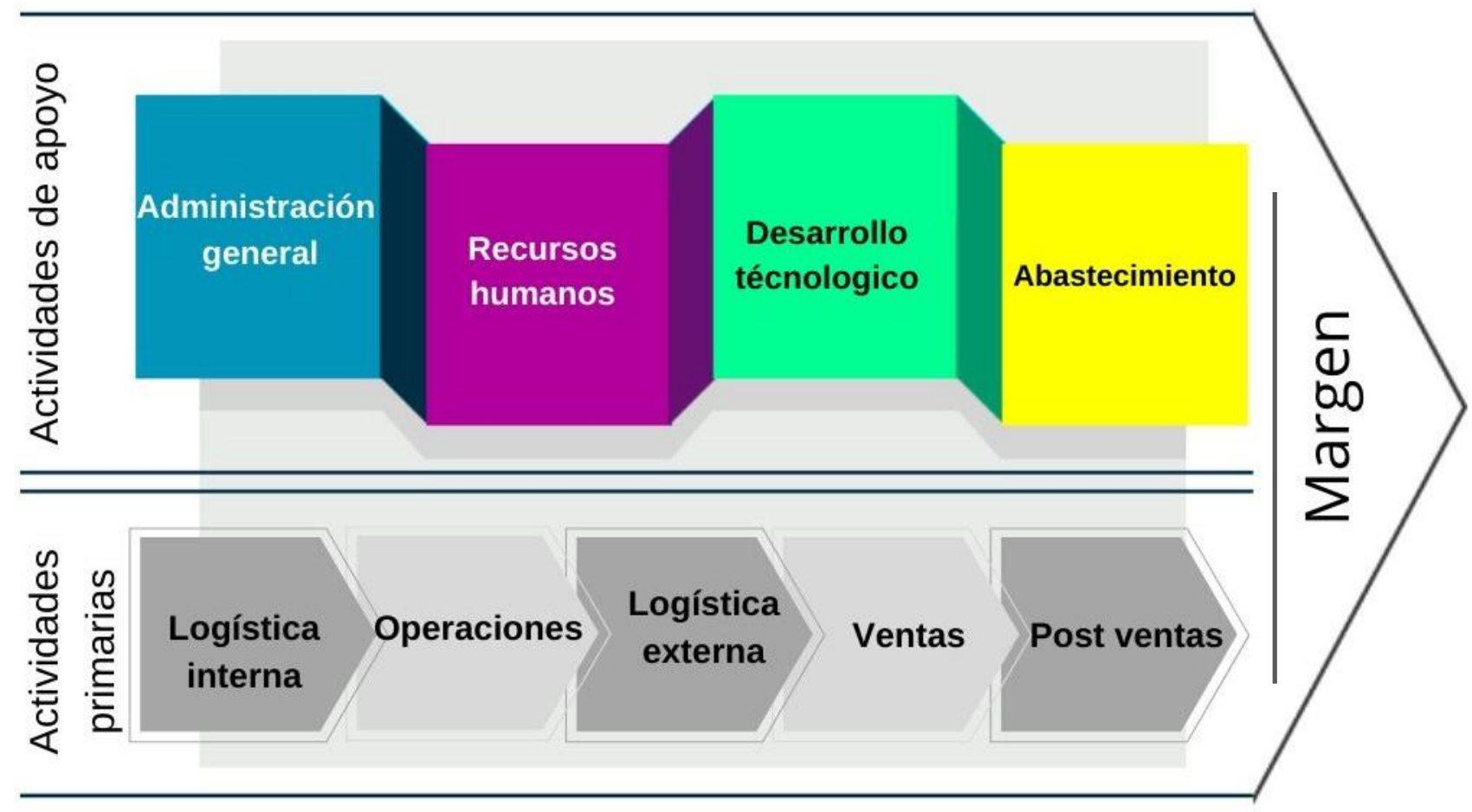

Figura 4. Esquema de propuesta de cadena de valor. Fuente: Elaboración propia

En este sentido, (Porter, 1985) argumenta que la capacidad de realizar actividades particulares y gestionar los vínculos entre estas actividades es una fuente de ventaja competitiva y distingue entre actividades primarias y actividades de apoyo, las actividades primarias son directamente relacionadas por la creación o entrega de un producto o servicio. Estas actividades primarias están vinculadas a actividades de apoyo que ayudan 
a mejorar su eficacia o eficiencia, cuanto más valor crea una organización, más rentable es probable que sea y cuando proporciona más valor a sus clientes, desarrolla una ventaja competitiva.

Valor creado y capturado - costo de crear ese valor = margen

En lugar de mirar los departamentos o los tipos de costos contables, la cadena de valor de Porter se centra en los sistemas y en cómo las entradas se convierten en las salidas compradas por los consumidores, por lo tanto se plantean propuestas para mejorar cada una de las actividades de la empresa Industria Acuícola Vikas. Cía. Ltda.

\section{Actividades Primarias}

Logística de entrada: en la figura 5 , se plantea un modelo de proceso de recepción de larva, insumos y balanceados, que son escenciales para la producción del camarón y en las figura 6,7 , se propone el formato de actas de recepción. 
Ariana Yamara Vivar Astudillo; Juan Carlos Erazo Álvarez; Cecilia Ivonne Narváez Zurita

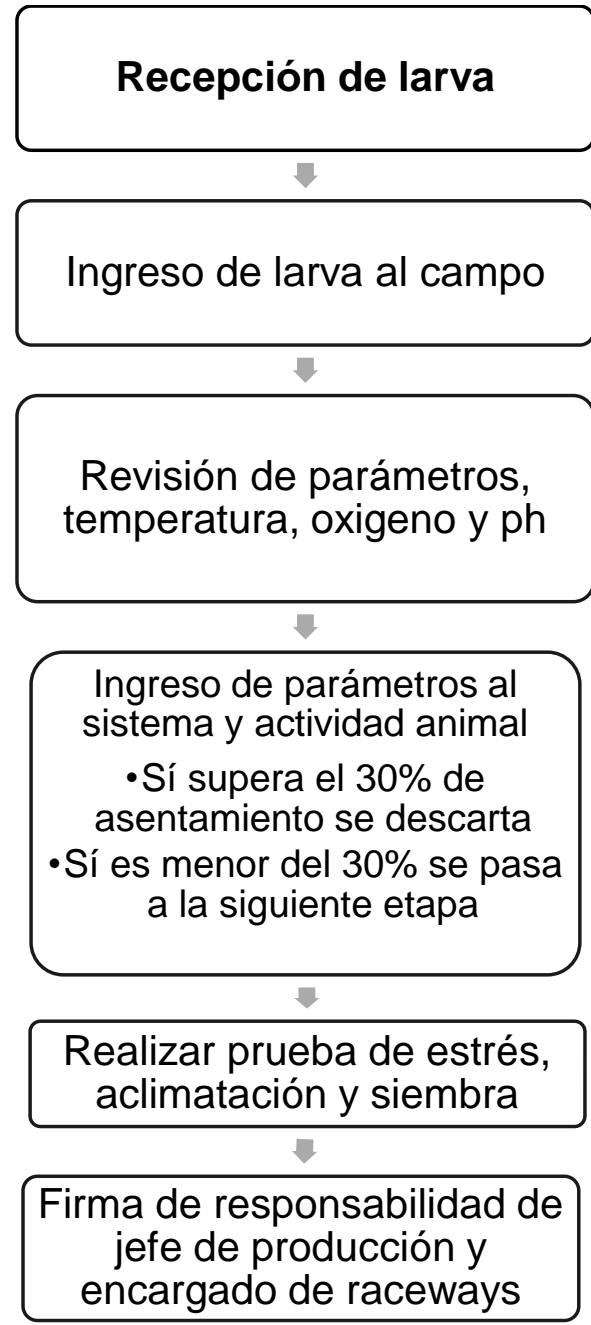

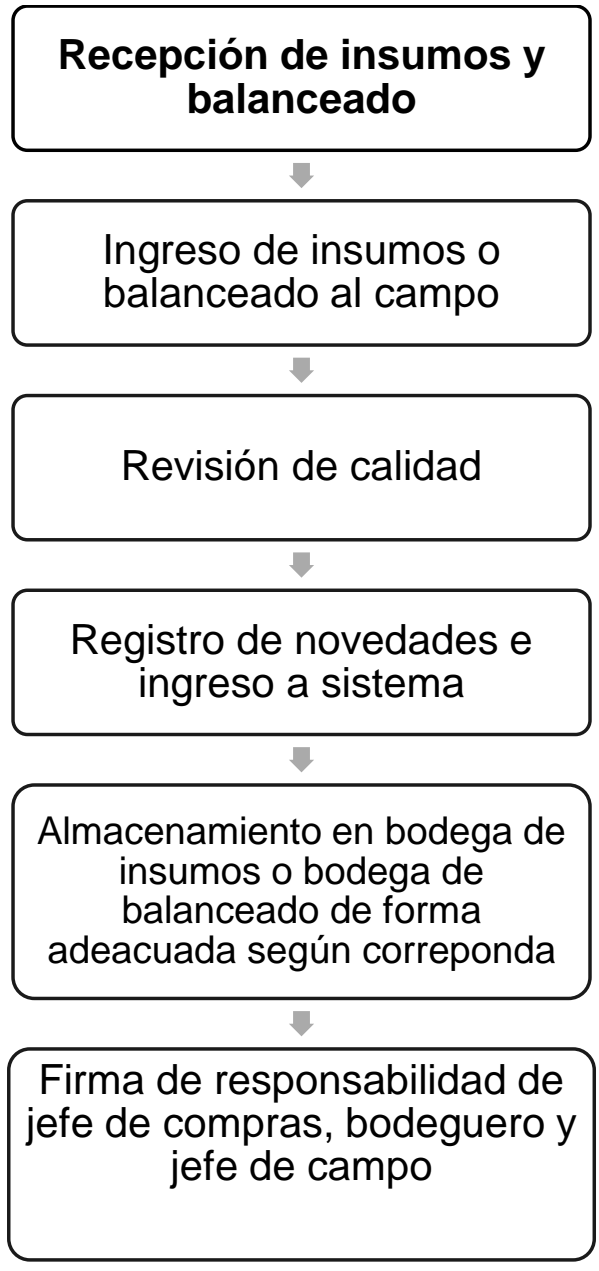

Figura 5. Proceso de recepción de larva, insumos y balanceados.

Fuente: Investigadores, 2020

\begin{tabular}{|c|c|c|c|c|c|}
\hline धथिikas & \multicolumn{5}{|c|}{ Acta de recepción diaria de insumos y balanceado } \\
\hline \multicolumn{6}{|l|}{ Fecha: } \\
\hline Tipo & Producto & Unidad & Peso total & Inspección & Firma resposabilidad \\
\hline & & & & & \\
\hline & & & & & \\
\hline
\end{tabular}

Figura 6. Formato de acta de recepción de insumos y balanceado.

Fuente: Investigadores, 2020 
Revista Arbitrada Interdisciplinaria KOINONIA

Año V. Vol V. N 10 . Julio - Diciembre 2020

Hecho el depósito de Ley: FA2016000010

ISSN: 2542-3088

FUNDACIÓN KOINONIA (F.K). Santa Ana de Coro. Venezuela.

Ariana Yamara Vivar Astudillo; Juan Carlos Erazo Álvarez; Cecilia Ivonne Narváez Zurita

\begin{tabular}{|c|c|c|c|c|c|}
\hline Gîkas & \multicolumn{5}{|c|}{ Acta de recepción de larva } \\
\hline \multicolumn{6}{|l|}{ Fecha: } \\
\hline Tinas & Peso & Temperatura & Oxígeno & $\mathrm{Ph}$ & Firma de responsabilidao \\
\hline & & & & & \\
\hline & & & & & \\
\hline & & & & & \\
\hline
\end{tabular}

Figura 7. Formato de acta de recepción de larva.

Fuente: Investigadores, 2020.

Logística externa: En la figura 8 semuestra el proceso de salida del producto desde su preparación para cosecha hasta la exportación a mercados internacionales, al igual de la figura 9 donde detalla el mismo.
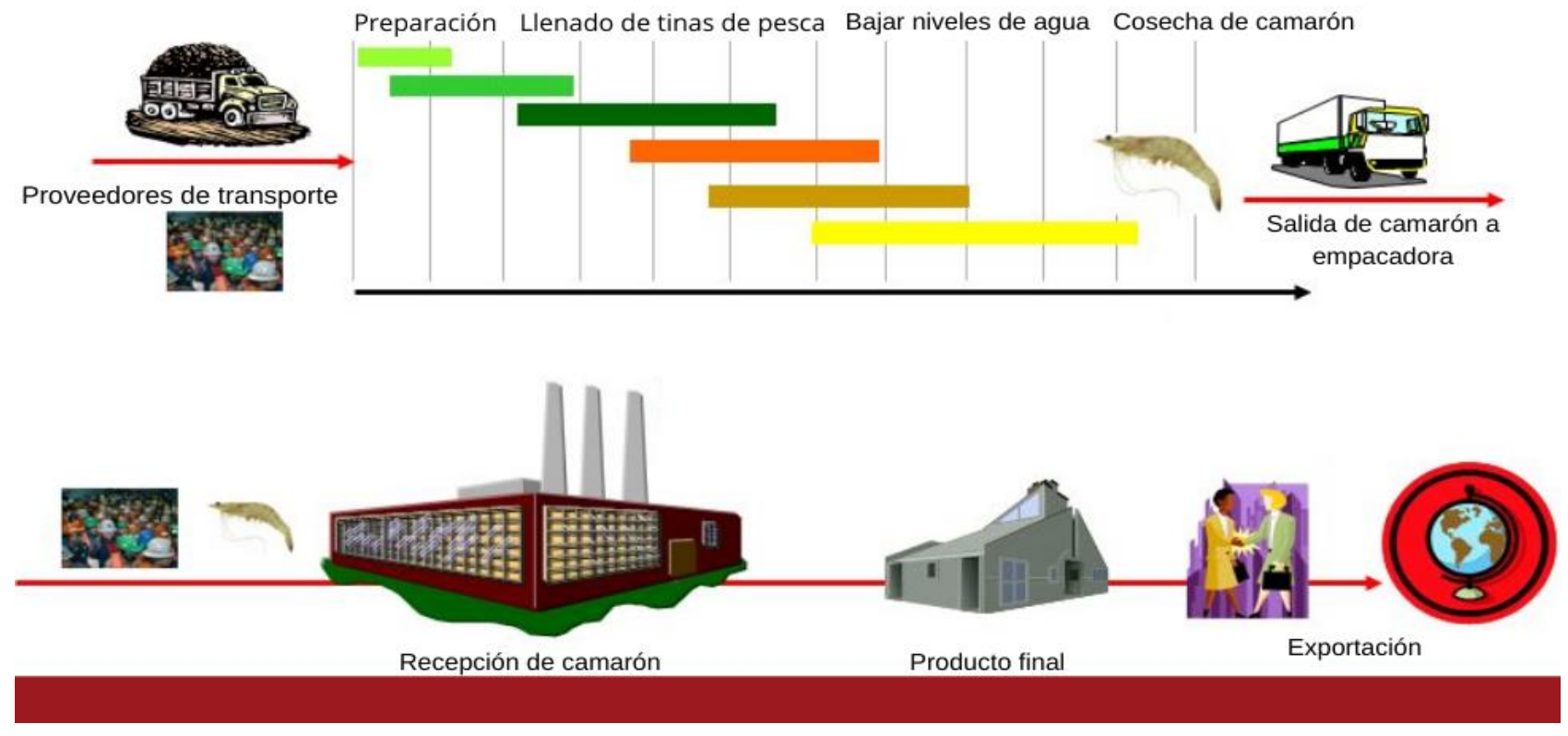

Figura 8. Proceso de salida de producto. 
Revista Arbitrada Interdisciplinaria KOINONIA

Año V. Vol V. N 10 . Julio - Diciembre 2020

Hecho el depósito de Ley: FA2016000010

ISSN: 2542-3088

FUNDACIÓN KOINONIA (F.K). Santa Ana de Coro. Venezuela.

Ariana Yamara Vivar Astudillo; Juan Carlos Erazo Álvarez; Cecilia Ivonne Narváez Zurita

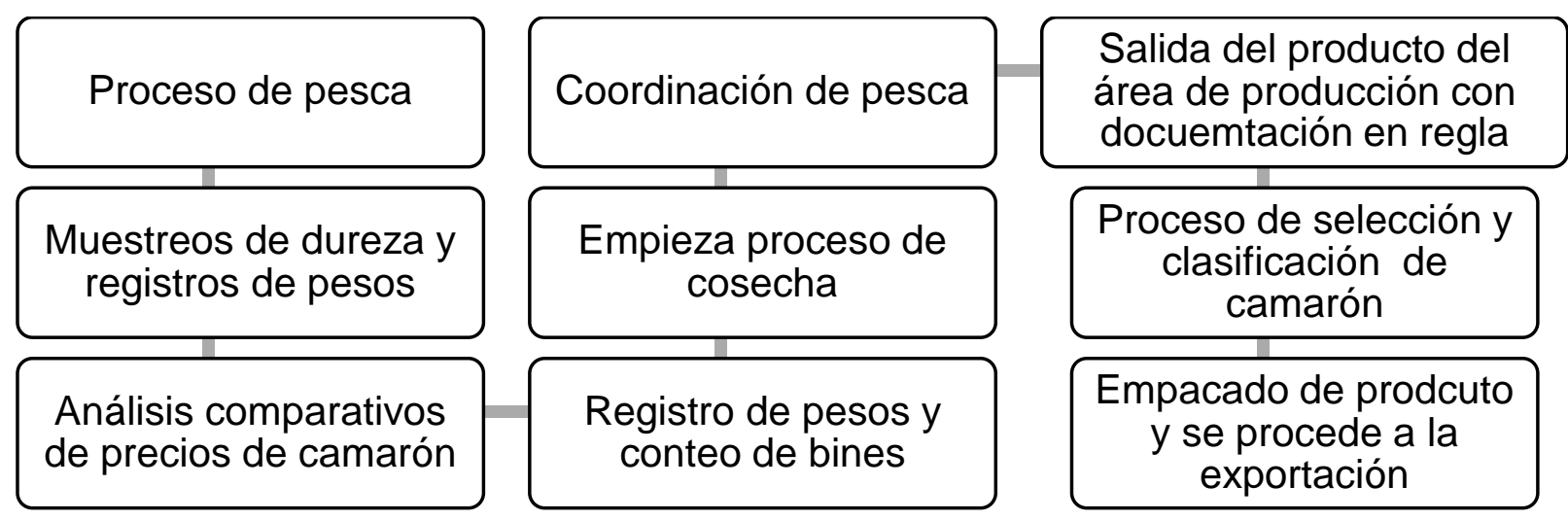

Figura 9. Detalle obtención de producto final

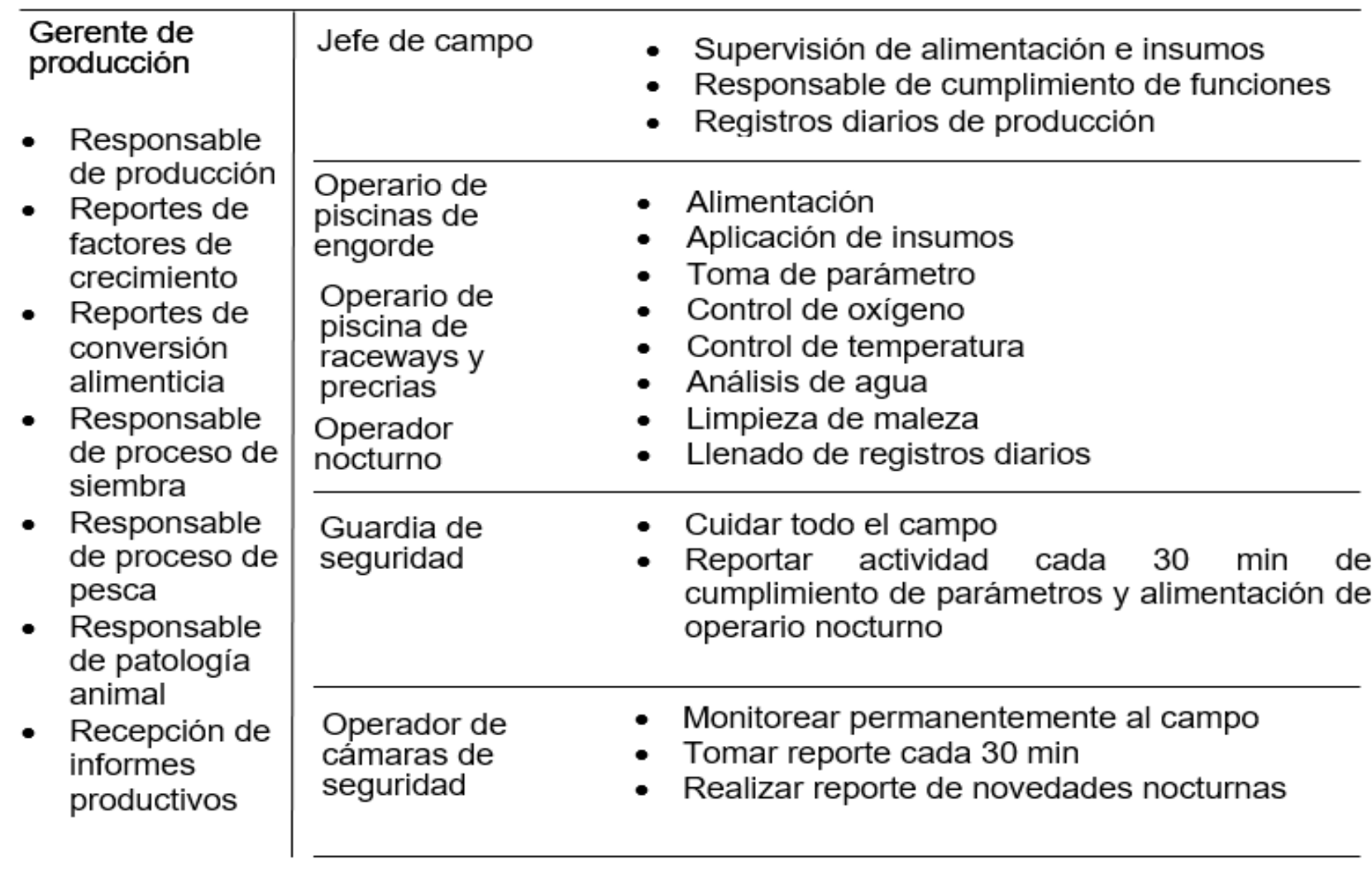

Figura 10. Funciones de área de producción.

Fuente: Investigadores, 2020. 
Operaciones: En la figura 10, se muestra el manual de funciones resumido con las actividades más importantes del personal que labora en campo.

Ventas: en la figura 11 se observa un planteamiento de diseño de tabla para los análisis de precios por de la empacadora, en la que detalla las tallas en entero y cola con el fin de tomar la mejor decision de venta.

\begin{tabular}{|c|c|c|c|c|c|c|c|c|c|c|c|c|}
\hline Oinass & \multicolumn{12}{|c|}{ Registro de precios de empacadoras } \\
\hline \multicolumn{13}{|l|}{ Fecha: } \\
\hline \multirow{2}{*}{\begin{tabular}{|c|} 
Nombre de \\
empacadora
\end{tabular}} & \multicolumn{5}{|c|}{ Tallas entero } & \multicolumn{6}{|c|}{ Tallas cola } & \multirow{2}{*}{$\begin{array}{r}\text { Decisión } \\
\text { de compra }\end{array}$} \\
\hline & \begin{tabular}{|l|l|l|l|l|}
$23-30$ & $30-40$ & $40-50$ & $50-60$ \\
\end{tabular} & $060-7070-80$ & $080-100$ & $0100-120$ & 120-140 & $16-2021-25$ & \begin{tabular}{|l|l|}
$526-30$ & $31-35$ \\
\end{tabular} & \begin{tabular}{|l|l|l|}
$56-40$ & $41-50$ \\
\end{tabular} & $51-60$ & $61-70$ & \begin{tabular}{l|l|l|}
72 & $91-110$ \\
\end{tabular} & \\
\hline & & & & & & & & & & & & \\
\hline & & & & & & & & & & & & \\
\hline & & & & & & & & & & & & \\
\hline & & & & & & & & & & & & \\
\hline
\end{tabular}

Figura 11. Análisis de precio de venta. Fuente: Investigadores, 2020.

Post ventas: En la figura 12 se presenta un modelo de registro de rendimiento camarón enviado de la empacadora, para llevar un control del producto y posteriormente receptar liquidación de venta.

\begin{tabular}{|c|c|c|c|c|}
\hline Oilkals & \multicolumn{4}{|l|}{ Registro de rendimientos de camarón en empacadora } \\
\hline Fecha & Clasificación & Talla & Rendimiento & Observaciones \\
\hline & & & & \\
\hline & & & & \\
\hline & & & & \\
\hline
\end{tabular}

Figura 12. Post venta de camarón.

Fuente: Investigadores, 2020. 


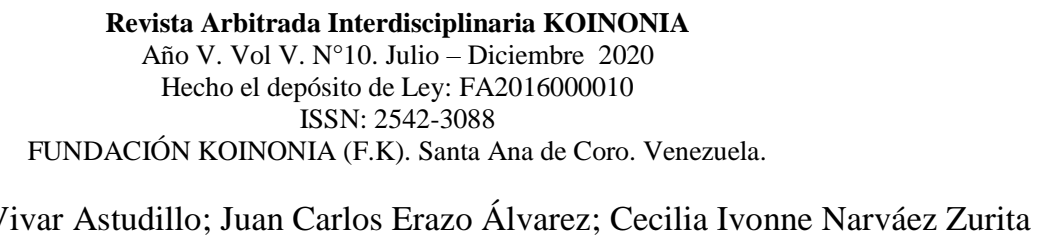

Ariana Yamara Vivar Astudillo; Juan Carlos Erazo Álvarez; Cecilia Ivonne Narváez Zurita

Actividades apoyo: Las empresas pueden mejorar aún más las actividades principales de su cadena de valor con actividades secundarias, las actividades de apoyo hacen precisamente eso, apoyan las actividades principales, generalmente juega un papel en cada actividad primaria, tienen como objetivo coordinar y apoyar sus funciones lo mejor posible entre sí al proporcionar insumos comprados, tecnología, recursos humanos y diversas funciones de gestión en toda la empresa.
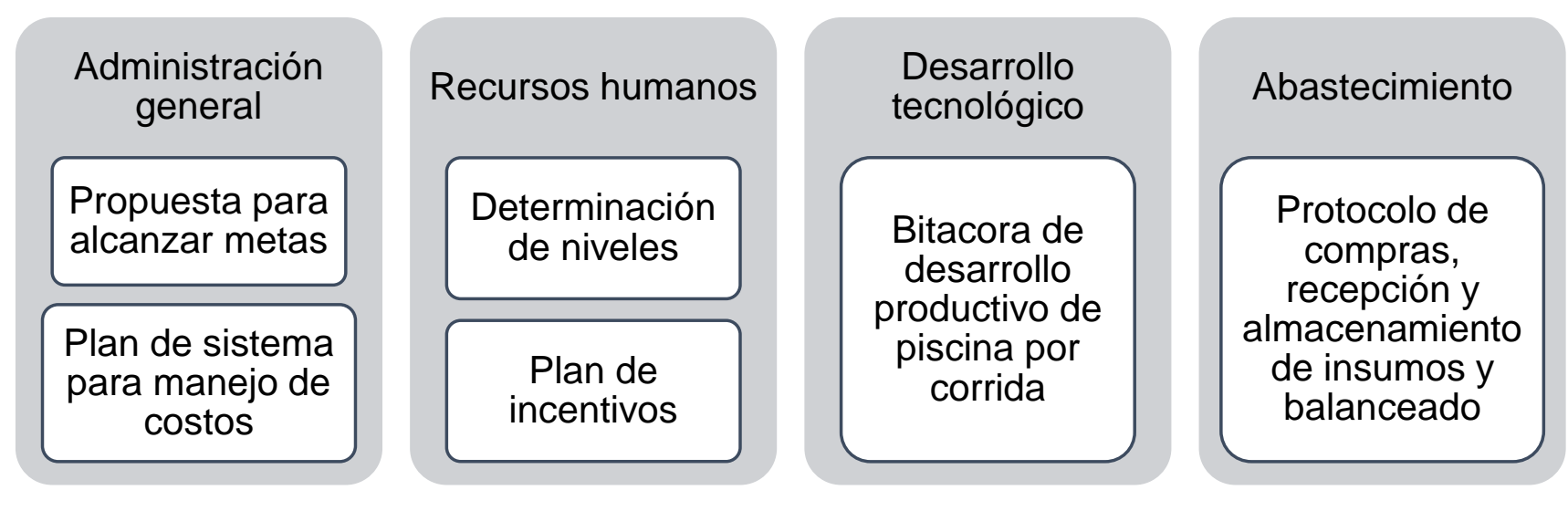

Figura 13. Propuesta de actividades de apoyo.

Fuente: Investigadores, 2020.

Administración general: En la Figura 14 se propone un sistema de pasos a realizar para alcanzar las metas de la empresa y en la figura 15 se muestra el plan de manejo para sistema de inventarios y costos.

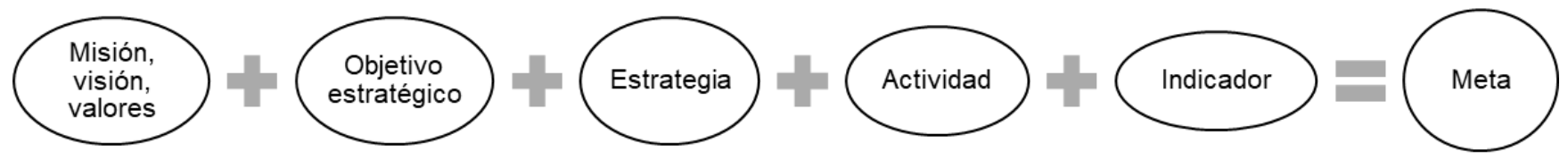

Figura 14. Propuesta para alcanzar la meta de la empresa.

Fuente: Investigadores, 2020. 


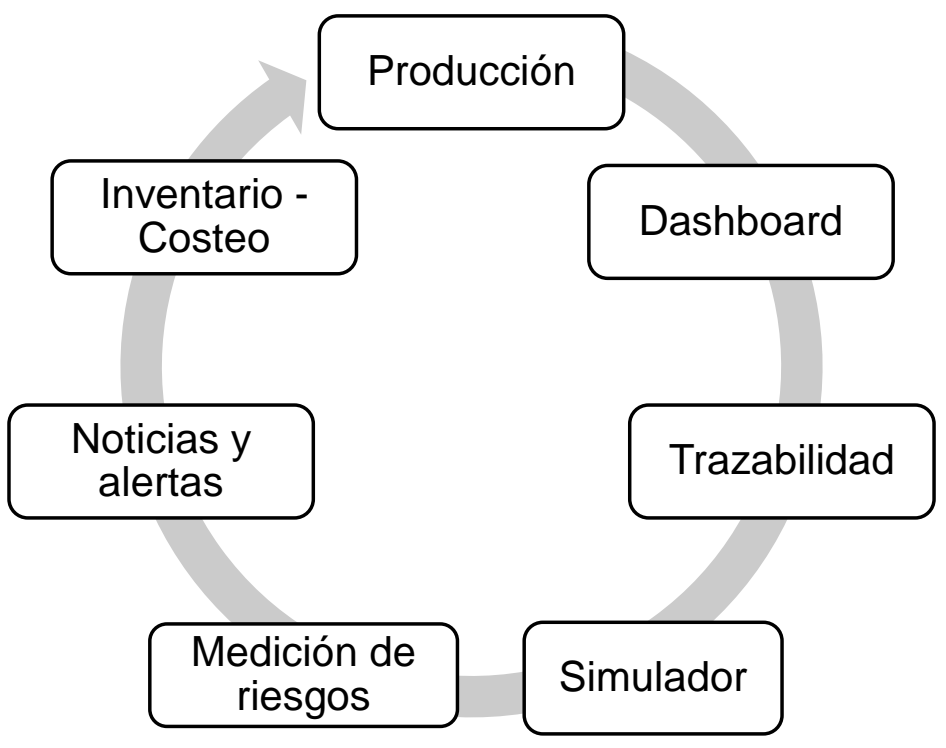

Figura 15. Plan de manejo para sistema de inventarios y costos.

Fuente: Investigadores, 2020.

Recursos humanos: La figura 16 presenta un plan de incentivos monetario y no monetarios para mejor el desempeño y productividad y en la figura 17 , se propone la determinación de niveles laborales.

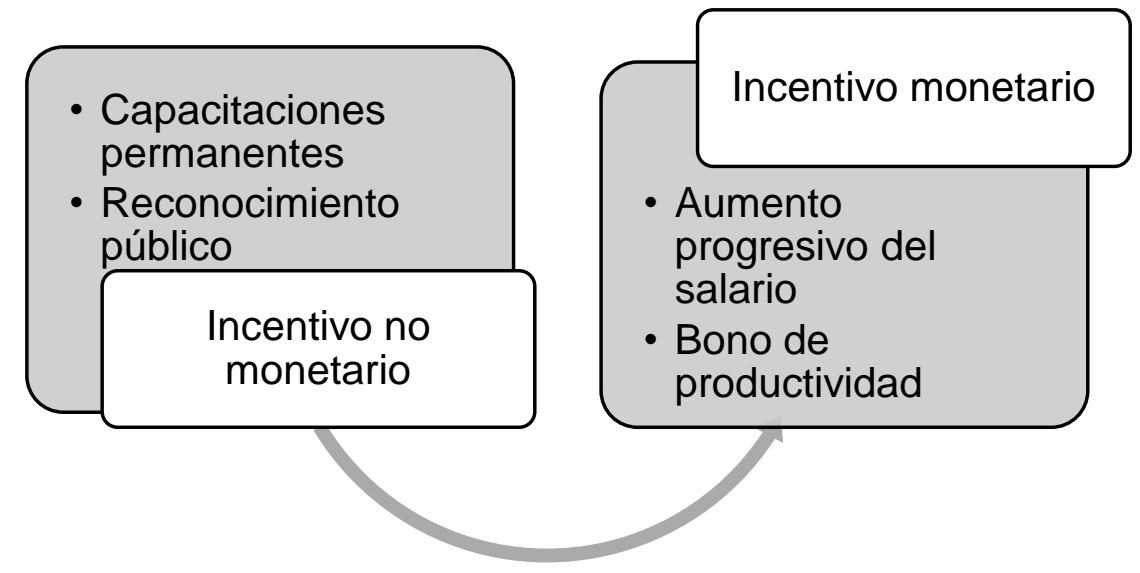

Figura 16.Plan de incentivos.

Fuente: Investigadores, 2020. 

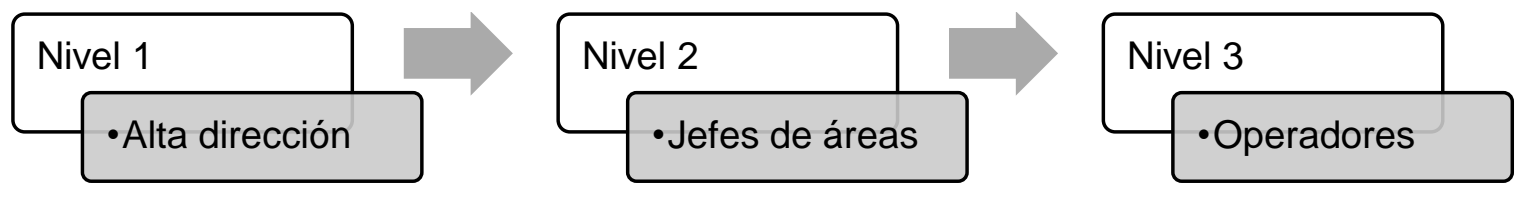

Figura 17. Determinación de niveles.

Fuente: Investigadores, 2020.

Desarrollo tecnológico: En la figura 18 se expone un modelo de bitácora de desarrollo tecnológico e innovación de procesos que desarrolla la empresa en cada corrida.

\begin{tabular}{|c|c|c|c|c|c|c|}
\hline \multirow{2}{*}{\multicolumn{2}{|c|}{\begin{tabular}{|l|l|}
\multicolumn{2}{|c|}{ Syikus } \\
Fecha Corrida
\end{tabular}}} & \multicolumn{5}{|c|}{ Bitacora de desarrollo e innovación de procesos } \\
\hline & & Piscina & Innovación & Seguimiento & Resultados & Observaciones \\
\hline & & & & & & \\
\hline & & & & & & \\
\hline & & & & & & \\
\hline & & & & & & \\
\hline
\end{tabular}

Figura 18. Propuesta de bitácora de desarrollo e innovación de procesos.

Fuente: Investigadores, 2020.

Abastecimiento: En la figura 19, se propone los pasos para realizar las compras de insumos, balanceados, materiales y herramientas, vehículos, entre otros. Con el fin de comprar lo necesario y a menor precios y optimizar costos.

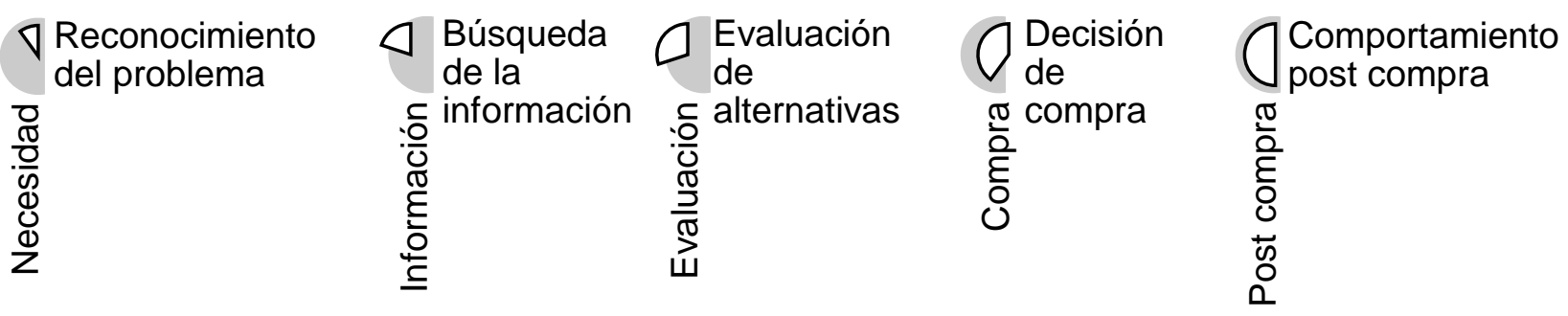

Figura 19. Propuesta de proceso de compra.

Fuente: Investigadores, 2020. 


\section{CONCLUSIONES}

La empresa mantiene una buena estructura organizacional en todas sus áreas, lo cual le permite tener un buen manejo en toda la cadena de valor, desde sus actividades primarias y de apoyo, sin embargo, es importante que la organización cuente con objetivos, metas, que sean cuantificables, medibles, por cuanto permitirá llegar al éxito empresarial de una manera más sencilla, además de administrar de una mejor manera los recursos disponibles basados en estrategias.

La organización tiene actualmente un manual de funciones, pero no tiene una escala salarial lo que puede resultar en una desmotivación de sus colaboradores, al igual que carece de planes de capacitaciones y procedimientos de evaluaciones de desempeño para medir a sus trabajadores lo que puede causar una deficiencia en la productividad. Los resultados indican que la empresa en el área financiera, aunque mantiene un correcto análisis y seguimiento del riesgo de los clientes, no posee un sistema de análisis de costos, en cuanto a la rentabilidad de los recursos propios,son revisados de una manera ocasional, lo que puede ocasionar problemas en su flujo de caja.

En el área productiva la compañía mantiene una correcta fluidez de información, lo que es muy importante para optimizar operaciones, sin embargo, no mantienen formatos completos para un correcto flujo de información y datos estadísticos productivos. En la proveeduría se mantienen tiempos de pedidos, stock mínimos y máximos, kardex de bodegas, pero existe una falencia que no se evalúan posibilidades de buscar proveedores alternativos a los actuales, lo que puede tener una consecuencia en los costos productivos.

\section{FINANCIAMIENTO}

No monetario

\section{AGRADECIMIENTOS}

A la Empresa Industria Acuícola Vikas Cía. Ltda; por el apoyo en el desarrollo de la investigación. 


\section{REFERENCIAS CONSULTADAS}

Ahokangas, P., Juho, A., \& Haapanen, L. (2010). Toward the theory of temporary competitive advantage in internationalization [Hacia la teoría de la ventaja competitiva temporal en la internacionalización]. Emerald Group Publishing Limited. https://doi.org/10.1108/S0749-6826(2010)0000012008

Amadeo, K. (2019). What Is Competitive Advantage? Three Strategies That Work. [¿Qué es la ventaja competitiva? Tres estrategias que funcionan]. Recuperado de https://n9.cl/36fx

Artieda, C. (2015). Análisis de los sistemas de costos como herramientas estratégicas de gestión en las pequeñas y medianas empresas (PYMES). [Analysis of cost systems as strategic management tools in small and medium-sized enterprises (PYMES)]. Revista Publicando, 2(3), 90-113. Recuperado de https://n9.cl/unwk

Baena, G. (2017). Metodología de la Investigación. [Investigation methodology]. México: Grupo Editorial Patria. Recuperado de https://n9.cl/dbo8

Banco Central del Ecuador. (2020). La economía ecuatoriana decreció -0,1\% en el tercer trimestre de 2019. [The Ecuadorian economy decreased $-0.1 \%$ in the third quarter of 2019]. Recuperado de https://n9.cl/n2k3

Basu, R. (2017). Managing Project Supply Chains.[Gestión de cadenas de suministro de proyectos]. Routledge.

Collis, D., \& Anand, B. (2019). The Limitations of Dynamic Capabilities. [Las limitaciones de las capacidades dinámicas]. Recuperado de https://n9.cl/i2yo

Crain, DW y Abraham, S. (2008). Uso del análisis de la cadena de valor para descubrir las necesidades estratégicas de los clientes. Emerald Group Publishing Limited. 36 (4): 29-39

Erazo, J. C., \& Narváez, C. I. (2020). Medición y gestión del capital intelectual en la industria del cuero - calzado en Ecuador.[Measurement and management of intellectual capital in the leather industry - footwear in Ecuador]. Revista Arbitrada Interdisciplinaria Koinonía, 437-467. http://dx.doi.org/10.35381/r.k.v5i9.662

Grant, R. (2010). Contemporary Strategy Analysis. [Análisis de la estrategia contemporánea]. John Wiley \& Sons.

Grimm, C., Lee, H., \& Smith, K. (2005). Strategy As Action. [Estrategia como acción]. Oxford University Press. 


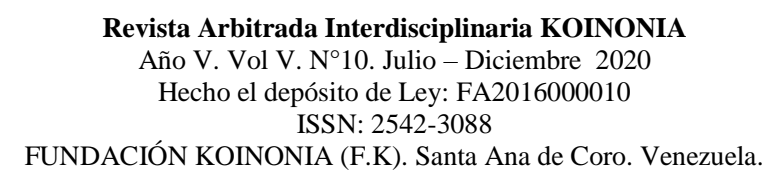

Ariana Yamara Vivar Astudillo; Juan Carlos Erazo Álvarez; Cecilia Ivonne Narváez Zurita

Heene , A., \& Sanchez, R. (2010). Enhancing Competences for Competitive Advantage. [Mejora de competencias para la ventaja competitiva]. Emerald Publishing Limited. https://doi.org/10.1108/S0749-6826(2010)0000012015

Hernández, R., Fernández, C., Baptista, P. (2014). Metodología de la Investigación. [Investigation methodology]. México: Editorial Mc - Graw - Hill Interamericana. Sexta edición

Jurevicius, O. (2013). Value Chain Analysis. [Análisis de la cadena de valor].Strategic Management Insight. Recuperado de https://n9.cl/sr98

Kaleka, A., \& Morgan, N. (2017). Which Competitive Advantages? Competitive Advantage- Market Performance Relationships in international markets. [¿Qué ventajas competitivas? Ventaja competitiva - Relaciones de desempeño del mercado en los mercados internacionales]. Journal of International Marketing. https://doi.org/10.1509\%2Fjim.16.0058

Kluyver, C., \& Pearce, J. (2015). Strategic Management : An Executive Perspective. Business Expert Press. [Gestión estratégica: una perspectiva ejecutiva. Prensa experta en negocios]. Recuperado de https://n9.cl//ogx

Magretta, J. (2014).Entender a Michael Porter: Guía esencial hacia la estrategia y la competencia. [Understanding Michael Porter: the essential guide to competition and strategy]. México: Grupo Editorial Patria S.A.

Maroto, J. (2017). Estrategica Competitiva.[Competitive Strategy]. Madrid: ESIC Editorial.

Musa, A., Firas, M., \& Mahmoud, A. (2014). The Extent of Applying Value Chain Analysis to Achieve and Sustain Competitive Advantage in Jordanian Manufacturing Companies. [El alcance de la aplicación del análisis de la cadena de valor para lograr y mantener una ventaja competitiva en las empresas manufactureras jordanas]. International Business Research, 179-188. Recuperado de http://dx.doi.org/10.5539/ibr.v7n8p179

Ortega, O. F., Erazo, J. C., \& Narváez, C. I. (2019). Evaluación técnica y financiera de proyectos productivos aplicando lógica difusa. [Technical and financial evaluation of productive projects applying fuzzy logic]. Cienciamatria, 298-327. https://doi.org/10.35381/cm.v5i1.268

Picón, J. A., Erazo, J. C., \& Narváez, C. I. (2019). Plan de expansión empresarial para la Empresa Transnexos del Grupo Industrial Graiman. [Business expansion plan for the Transnexos Company of the Graiman Industrial Group]. Revista Arbitrada Interdisciplinaria Koinonía, 274-308. http://dx.doi.org/10.35381/r.k.v4i1.459 
Ariana Yamara Vivar Astudillo; Juan Carlos Erazo Álvarez; Cecilia Ivonne Narváez Zurita

Piedrahita, Y. (2018). La industria de cultivo de camarón en Ecuador. [The shrimp farming industry in Ecuador]. Recuperado de https://n9.cl/eu13

Plain, R. (2018). World pork production in line with population growth. [Producción mundial de carne de cerdo en línea con el crecimiento de la población]. Recuperado de https://n9.cl/pd93

Porter, M. (1985). Competitive advantage.[Ventaja competitiva]. Recuperado de https://n9.cl/gd1y6

Porter, M. (2015). Estrategia Competitiva. Técnicas para el análisis de los sectores industriales y la competencia. [Competitive strategy. Techniques for the analysis of industrial sectors and competition]. Mexico: Grupo Editorial Patria.

Presutti , W., \& Mawhinney, J. (2013). Understanding the Dynamics of the Value Chain.[Comprender la dinámica de la cadena de valor]. Business Expert Press.

Simatupang, T., Piboonrungroj, P., \& Williams, S. (2016). The emergence of value chain thinking. [El surgimiento del pensamiento de la cadena de valor]. International Journal of Value Chain Management. https://doi.org/10.1504/IJVCM.2017.082685

(C2020 por los autores. Este artículo es de acceso abierto y distribuido según los términos y condiciones de la licencia CreativeCommons Atribución-NoComercial-Compartirlgual 4.0 Internacional (CC BY-NC-SA 4.0) (https://creativecommons.org/licenses/by-nc-sa/4.0/). 